ISSN 2466-2232 (Print)

ISSN 2466-2100 (Online)

\title{
MIG Arc Effects on Root Penetration of Laser Hybrid Welded T-Joints
}

\author{
Johannes Gaig1 ${ }^{*, \dagger}$ \\ *Pre-Development Engineer at MAHLE GmbH, Stuttgart, 70186, Germany
}

†Corresponding author : jgaigl@gmail.com

(Received April 5, 2020 ; Revised May 11, 2020 ; Accepted June 10, 2020)

\begin{abstract}
The effects of MIG parameters on a laser hybrid process are explored in this paper. In particular, the correlation between the MIG arc length and seam parameters. Seam Parameters are the seam width and the root penetration of fillet welds on T-joints. By variation of MIG parameters, such as current, voltage, and frequency, an increase of root penetration of up to $30 \%$ is reached. Based on this data, the link between intensity of the MIG process, arc length, and root connection are worked out. The base material is made out of AlMg3Mn and the filler wire out of AlSi5.
\end{abstract}

Key Words : Laser MIG hybrid, Welding, T-joints, Root connection, Aluminum alloy, Parameter variation, Arc length, Intensity

\section{Introduction}

The coupling of laser and MIG processes to form a hybrid process with a single melting pool offers advantages, compared to each process individually. These advantages are characterized by high welding speed, gap bridging capability and welding depth ${ }^{1,2)}$. At the same time, the low line energy leads to a reduction of thermal stress and thus to low distortion ${ }^{3)}$. First trials have shown that these attributes are perfectly applicable for 3-D joining applications. In particular the joining of only a few millimeters thick sheet metal structures of cold worked aluminum alloys, which should meet high quality requirements. Pre-processing tolerances, which could cause gaps of more than one millimeter, can be compensated in the welding process. This is possible by means of position-specific increased filler material addition.

Despite some parameters, the laser hybrid process is just partially investigated. There is a lack of studies on quality parameters, such as those that influence the root connection $^{4)}$. This decisive parameter for the strength of the joint is adjusted through the laser power only ${ }^{5,6}$. It is even postulated that an increase in welding depth cannot be influenced by the MIG contribution ${ }^{7}$.

Studies on process parameters such as welding speed or wire feed rate are available on a large scale $\mathrm{s}^{3,4,8,9)}$. They have even been carried out using artificial neural networks and genetic algorithms ${ }^{10)}$. These investigations were carried out on butt, lap, and flanged joints. If processes are optimized for welding depths, it is done exclusively at blind seams ${ }^{11,12)}$. Investigations of T-joints are available on a very small extent and require seam preparation $^{13)}$, or are produced by welding through the belt plate ${ }^{14)}$.

Due to these conditions, this paper analyzes the penetration of fillet welds of the T-joint. Specifically, the effect of the MIG process on the root connection is investigated.

\section{Used Setup}

The setup is comprised of an articulated robot and a Fronius laser hybrid welding head, with an integrated Trans Puls Synergic welding system. The laser is an YPG fiber laser YLR-5000. The laser runs in front of the MIG torch, piercing with a $5^{\circ}$ angle and the MIG welding head follows $3 \mathrm{~mm}$ behind the $-1 \mathrm{~mm}$ focal position, piercing with a $35^{\circ}$ angle. The Welding speed is $45 \mathrm{~mm} / \mathrm{s}$, a laser power of $4.1 \mathrm{~kW}$ and focal diameter of $220 \mu \mathrm{m}$. The sheets are out of AlMg3Mn, with a thickness of $3.5 \mathrm{~mm}$ and the filler wire is out of AlSi5. The 
gap between the plates of the T-joint is $0 \mathrm{~mm}$.

The temporal characteristics of voltage and current of the MIG power source were recorded using a HKS measurement system. The system consists of a Weld QAS measuring computer, the WeldAnalyst software and the P1000 process sensor. The sampling frequency was selected with $52 \mathrm{kHz}$, whereby the measurement error is $\pm 1 \%$.

\section{Variated parameters}

In order to determine the effect of the MIG arc length on the root connection $A_{\mathrm{W}}$, the arc length is varied in the following. The arc length is essentially influenced

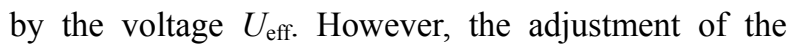
voltage $U_{\text {eff }}$ mandates additional parameter adaption to ensure a controlled material transfer.

If the voltage in the welding process is changed, the current also adjusts. The filler wire will be partially melted in the base current phase and detached in the pulse current phase. If the base current increases, the pulse frequency also has to be increased to prevent the arc from moving up the wire too high in the pulse current phase. An unstable arc and filler wire drop, too large for a stable process would be the consequences. In addition, if the base current increases, it may also be necessary to increase the impulse current. This raises the detaching pinch force and thus the probability for a stable filler wire drop separation. Key figures of the used parameter set are summarized in Fig. 1. These figures are clustered through the auxiliary variable arc correction $L_{\mathrm{K}}$.

Fig. 2 illustrates the measured values of the arc length and arc correction $L_{\mathrm{K}}$. If the arc length is given in relation to the stickout, the resulting lengths are $35 \%, 40 \%$ and $45 \%$. In the considered range of the arc correction $L_{\mathrm{K}}$, both parameters change relatively by the same amount.

\section{Determination of seam width and MIG power}

To analyze the effect of the arc correction $L_{\mathrm{K}}$ to weld seam properties, this was varied from $L_{\mathrm{K}}=-15 \%$ to $L_{\mathrm{K}}=$ $-1 \%$. Other process parameters are invariant. Cross sections of the weldings are presented in Fig. 3. These cross sections show with decreasing arc correction $L_{\mathrm{K}}$ an undercut on the weld seam surface evolving and in-
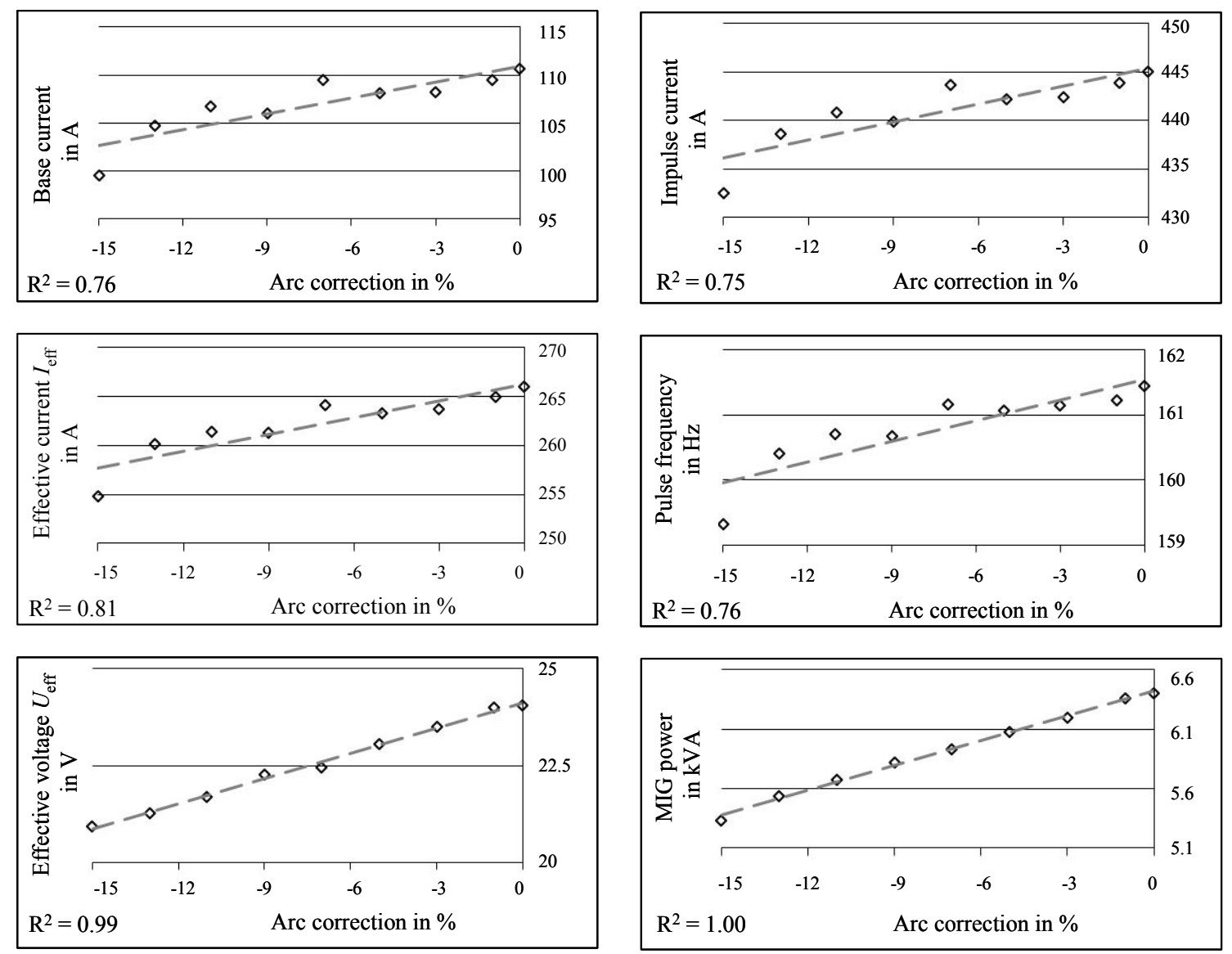

Fig. 1 Process parameters of the MIG function with regards to arc correction 

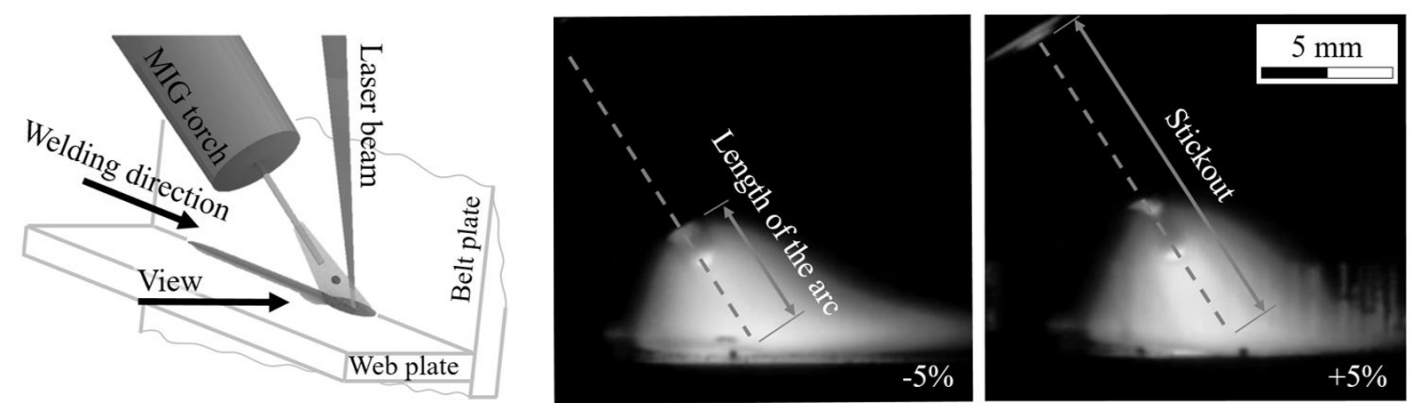

\begin{tabular}{|l|c|c|c|c|c|}
\hline \multirow{2}{*}{ Process parameter } & \multirow{2}{*}{ Symbol } & \multicolumn{3}{|c|}{ Status } & \multirow{2}{*}{ Unit } \\
\cline { 3 - 6 } & & 1 & 2 & 3 & \\
\hline Voltage & $U_{\text {eff }}$ & 23.2 & 24.1 & 25.0 & $\mathrm{~V}$ \\
\hline Length of the arc & $l_{\text {Arc }}$ & 4.9 & 5.6 & 6.3 & $\mathrm{~mm}$ \\
\hline Number of measurements & $\mathrm{n}$ & 5 & 5 & 5 & - \\
\hline Standard deviation & $\mathrm{SD}$ & 0.03 & 0.04 & 0.04 & $\mathrm{~mm}$ \\
\hline $\begin{array}{l}\text { Length of the arc regarding Stickout SO } \\
\left(S O_{\text {MIG,Alu }}=14 \mathrm{~mm}\right)\end{array}$ & $\frac{l_{\text {Arc }}}{S O_{\text {MIG }}}$ & 35 & 40 & 45 & $\%$ \\
\hline Arc correction & $L_{\mathrm{K}}$ & -5 & 0 & +5 & $\%$ \\
\hline
\end{tabular}

Fig. 2 Photos of the arc length with regards to voltage or arc correction $L_{\mathrm{K}}$
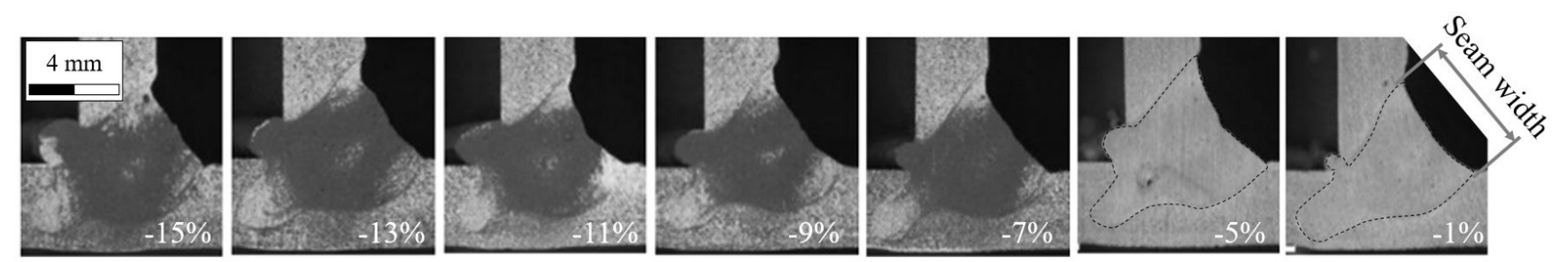

Fig. 3 Cross sections with seam width $b_{\text {Seam }}$ in regards to the arc correction $L_{\mathrm{K}}$
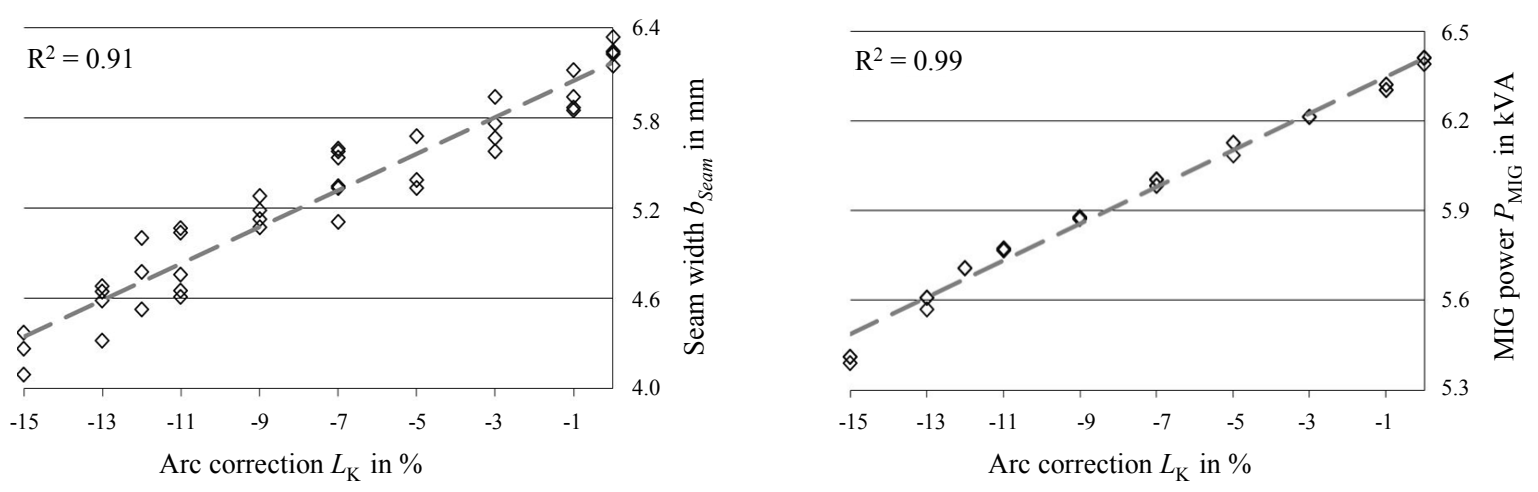

Fig. 4 Seam width $b_{\text {Seam }}$ and power $P_{\text {MIG }}$ plotted over the arc correction $L_{\mathrm{K}}$

creasing in size. Also the melt spill out at the weld root increases with decreasing arc correction $L_{\mathrm{K}}$. This indicates a greater root connection $A_{\mathrm{W}}$. This change represents also a decline in quality. However, this paper aims to provide a basic understanding of the interaction between MIG arc parameters and the root connection. This understanding should be used in comparable applications to optimize the weld seam quality regarding the assurance of the root connection.
For further investigations the seam width $b_{\text {Seam }}$ and root connection $A_{\mathrm{W}}$ were measured on the cross sections of Fig. 3 and on additional samples. With increasing arc correction $L_{\mathrm{K}}$, respectively the voltage, the seam width $b_{\text {Seam }}$ and MIG power $P_{\text {MIG }}$ increase too, as shown in Fig. 4. For a more profound understanding of the influence of these parameters on the root connection $A_{\mathrm{W}}$, they will have to be related with the intensity of the MIG arc. 

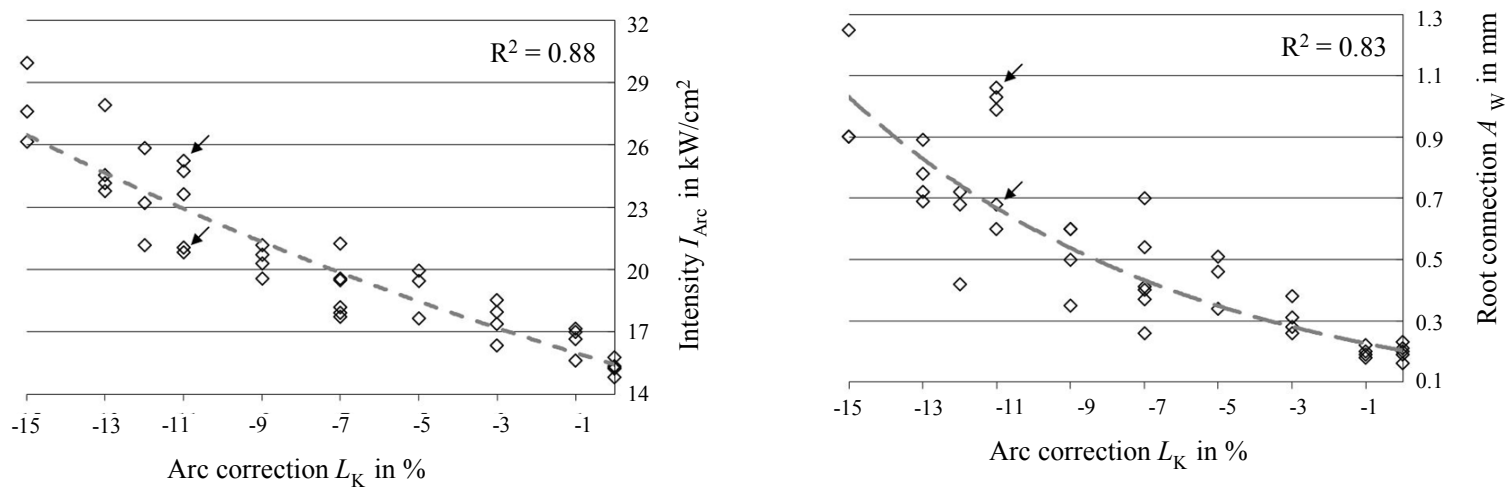

Fig. 5 Correlation of the intensity $I_{\mathrm{Arc}}$ and the output variable root connection $A_{\mathrm{W}}$

\section{Intensity of the MIG arc and the root connection of the T-joint}

If an even distribution and circular intensity of the MIG arc is presumed, the arc intensity $I_{\text {Arc }}$ can be determined by means of the MIG power $P_{\mathrm{MIG}}$ and the seam width $b_{\text {Seam }}$. This approximation is summarized in equation (1).

$$
I_{\mathrm{Arc}}=\frac{P_{\mathrm{MIG}}}{A_{\mathrm{Arc}}}=\frac{4 U_{\mathrm{eff}} I_{\mathrm{eff}} \eta_{\mathrm{th}}}{\pi \emptyset_{\mathrm{Arc}}{ }^{2}} \approx \frac{4 U_{\mathrm{eff}} I_{\mathrm{eff}} \eta_{\mathrm{th}}}{\pi b_{\mathrm{Seam}}{ }^{2}}
$$

With the thermal efficiency $\eta$ th of the MIG process assumed to be $90 \%$, the calculated intensity $I_{\text {Arc }}$ is plotted over the arc correction $L_{\mathrm{K}}$, as shown in Fig. 5. With decreasing arc correction $L_{\mathrm{K}}$, the intensity $I_{\text {Arc }}$ and the root connection $A_{\mathrm{W}}$ rise. The rise of both functions is not linear. Even though the parameter adjustment of the arc correction $L_{\mathrm{K}}$ lead to linear changes in seam width $b_{\text {Seam }}$ and MIG power $P_{\text {MIG }}$. The reasons for the non-linearity is the quadratic consideration of the seam width $b_{\text {Seam }}$ in equation (1).

The causal relationship between the functions is the change in heat flow. The increase of the intensity $I_{\text {Arc }}$ leads to changes in heat transfer and the melting behavior. These changes in heat conduction influence the root connection $A_{\mathrm{W}}$ and the melt emerging at the weld root.

The scattering of the data points in Fig. 5 is high, which can be traced back to the process. For example, the determined measured values of the arc correction $L_{\mathrm{K}}=-11 \%$ have to be considered (see arrows in Fig. 5). Three measured values with high intensities $I_{\text {Arc }}$ correlate with high root connection $A_{\mathrm{W}}$. The same applies to two measured values with low intensities $I_{\text {Arc }}$ and low root connection $A_{\mathrm{W}}$.

Nonetheless, these results show that an increase of the root connection $A_{\mathrm{W}}$ of approximately $1.1 \mathrm{~mm}(+30 \%)$ can be achieved in the considered area of the arc cor- rection $L_{\mathrm{K}}$. This is done exclusively by adjusting the MIG parameters of the laser hybrid process.

ORCID: Johannes Gaigl: https://orcid.org/0000-0002-7586-5055

\section{References}

1. P. Kah, A. Salminen and J. Martikainen, The influence of parameters on penetration, speed and bridging in laser hybrid welding, Mechanika, University of Technology, Finland (2011).

2. P. Kah, A. Salminen and J. Martikainen, Laser-arc hybrid welding processes (Review), The Paton Weld. J. 6 (2010).

3. C. Sommitsch, G. Posch, T. Weinberger, G. Figner and Neue Fügetechniken mit höherer Prozesssicherheit, Bergund Hüttenmännische Monatshefte, Springer Verlag, Berlin, Germany (2010).

4. I. Bunaziv, O. M. Akselsen, A. Salminen and A. Unt, Fiber laser-MIG hybrid welding of $5 \mathrm{~mm} 5083$ aluminum alloy, J. Mater. Process. Technol. 233 (2016).

5. W. M. Steen, Arc augmented laser processing of materials, J. Appl. Phys. 51 (1980).

6. C. Bagger and F. O. Olsen, Review of laser hybrid welding, J. Laser Appl. 17 (2005).

7. F. Reich, Laser-MIG-Hybridschweißen von Aluminiumlegierungen, Aktuelle Informationen aus dem Institut für Schweißtechnik und Fügetechnik der RWTH Aachen, ISF Direkt 31, Freundeskreis des Instituts für SchweiBtechnik e.V., RWTH Aachen, Germany (2005).

8. J. Ji, Prozessporen beim Nd:YAG-Laserstrahl-MSGHybridschweißen von Aluminiumlegierungen - Teil 2: Strategie zu ihrer Vermeidung, Schweißen und Schneiden 59, Heft 10 (2007).

9. B. Acherjee, Laser Arc Hybrid Welding, Advances in Laser Materials Processing, Second Edition, Chapter 9 (2018).

10. S. Chakil and S. Ghosal, A GA-ANN hybrid model for prediction and optimization of $\mathrm{CO}_{2}$ laser-MIG Hybrid welding process, Int. J. Automotive Mech. Eng. (IJAME), (2015). 
11. C. Walz, T. Seefeld and G. Sepold, Nahtgeometrie und Proze-ßstabilität beim Laser-MIG-Schweißen, Laser Opto. 33(H.2) (2001) 64-67.

12. L. Bidi, S. Mattei, E. Cicala, H. Andrzejewski, P. Le Masson and J. Schroeder, The use of exploratory experimental designs combined with thermal numerical modelling to obtain a predictive tool for hybrid laser/MIG welding and coating processes, Opt. Laser Technol. 43 (2011) 537-545.
13. K. Nilsson, H. Engström and A. Kaplan, Influence of butt- and T-joint preparation in laser arc hybrid welding, International Institute of Welding, Copenhagen, Denmark (2002) Doc. XII-1732-02.

14. C. Li and L. Liu, Investigation on weldability of magnesium alloy thin sheet T-joints: arc welding, laser welding, and laser-arc hybrid welding, Int. J. Adv. Manuf. Technol. 65 (1-4) (2013). 